\title{
Precipitation Behavior of Copper, Tin and Manganese Sulfide at High Temperature in $\mathrm{Fe}-10 \% \mathrm{Cu}-0.5 \% \mathrm{Sn}$ Alloys
}

\author{
Ken-ichi YAMAMOTO, ${ }^{1)}$ Hiroyuki SHIBATA ${ }^{2)}$ and Shozo MIZOGUCHI ${ }^{2)}$ \\ 1) Environment \& Process Technology Center, Technical Development Bureau, Nippon Steel Corporation, 20-1 Shintomi, \\ Futtsu-city, Chiba 293-8511 Japan. $\quad$ 2) Institute of Multidisciplinary Research for Advanced Materials, Tohoku University, \\ 2-1-1 Katahira, Aoba-ku, Sendai 980-8577 Japan.
}

(Received on August 29, 2005; accepted on October 6, 2005)

\begin{abstract}
Tramp elements such as Cu or Sn cause a severe hot shortness. Any tramp elements have been rejected and diluted below a certain limit by the use of virgin iron source. On the other hand, the steel properties are improved if Cu precipitates are very fine and uniformly dispersed in steels. $\mathrm{Cu}$ is the useful alloying element for increasing hardness and improving of $r$-value. Recently, it has been found that MnS precipitates have a good positive effect on the heterogeneous precipitation of $\mathrm{Cu}$ in grains. In this study a confocal scanning laser microscope with an infrared image furnace was used to carry out the in-situ observation of precipitation behavior at high temperature. To estimate the phase diagram, alloys were analyzed by a differential scanning calorimetry (DSC) method. It is clear that the domain of $\gamma$ Fe phase becomes smaller and the domain of the liquid phase becomes larger with the addition of Sn. As a result of observation by the confocal laser microscope, the number of precipitates increased at higher temperatures with MnS than without $\mathrm{MnS}$. The observed precipitates are classified into three types. Type "I" is the Cu (Sn) precipitate at the $\gamma \mathrm{Fe}$ grain boundary. Type "II" is the precipitate found in the $\gamma \mathrm{Fe}$ grains. One is the $\mathrm{Cu}(\mathrm{Sn})$ and another complex precipitate is composed of $\varepsilon \mathrm{Cu}$, (Mn, $\mathrm{Cu}) \mathrm{S}$ and $\mathrm{Cu}_{7.2} \mathrm{~S}_{4}$. Type "III" is the smallest $\varepsilon \mathrm{Cu}$ precipitate in the $\alpha \mathrm{Fe}$ grains. They nucleated after $\gamma / \alpha$ phase transformation and the size is less than $100 \mathrm{~nm}$.
\end{abstract}

KEY WORDS: copper steel; tramp element; tin; interstitial-free (IF) steel; precipitation; MnS; confocal laser microscope; transmission electron microscopy; liquid $\mathrm{Cu}$; $\varepsilon$-phase.

\section{Introduction}

Tramp elements such as copper $(\mathrm{Cu})$ or tin $(\mathrm{Sn})$ in steels are generally regarded as harmful because those elements cause the hot shortness. $\left.{ }^{1-6}\right)$ The enrichment of $\mathrm{Cu}$ due to the preferential oxidation of iron on the surface takes place when the steels containing $\mathrm{Cu}$ are kept at high temperature under an oxidizing atmosphere. Once $\mathrm{Cu}$ content exceeds the solubility limit in $\gamma \mathrm{Fe}, \mathrm{Cu}-\mathrm{Fe}$ alloy precipitates on the surface. This $\mathrm{Cu}-\mathrm{Fe}$ alloy will be melted if the temperature is above the melting point. Then the liquid $\mathrm{Cu}-\mathrm{Fe}$ alloy easily wets steel and penetrates into $\gamma \mathrm{Fe}$ grain boundaries to tear. Sn will enhance the precipitation of $\mathrm{Cu}$ because $\mathrm{Sn}$ reduces the solubility of $\mathrm{Cu}$ in $\gamma \mathrm{Fe}$.

In general, any tramp elements in steel have been rejected below a certain limit to avoid hot shortness. In steelmaking process the use of a large amount of virgin iron source is inevitable at any cost to dilute the steel contaminated by tramp elements. Recently, Hasegawa et al. ${ }^{7)}$ has found that MnS precipitates have a good positive effect on the heterogeneous precipitation of $\mathrm{Cu}$ in the grains. Therefore it will be expected that steels containing $\mathrm{Cu}$ are free from the hot shortness.

On the other hand, the steel properties are improved if $\mathrm{Cu}$ precipitates are very fine and uniformly dispersed in steels. $^{8-13)}$ In extra-low-carbon titanium-added interstitial- free (IF) steel sheets, $\mathrm{Cu}$ is the useful alloying element for increasing hardness and improving $r$-value. The mechanism of this improvement of hardness and deformability has been proposed due to the precipitation $\varepsilon \mathrm{Cu}$ of nano-meter size in IF steels. ${ }^{14,15)}$

As for Sn in steel, some properties have been discussed. ${ }^{5,11,16,17)}$ However, the precipitation and transformation behaviors at high temperatures in steel containing $\mathrm{Cu}$ and/or Sn have not been sufficiently made clear yet. Therefore in view of precipitation behavior of the liquid $\mathrm{Cu}$ regarded as equivalent to that of hot shortness, $\mathrm{Fe}-10$ mass $\% \mathrm{Cu}$ alloy system was chosen and $\mathrm{Sn}$ was added to this system. In this system the purpose of the present study is to make it clear where and how the $\mathrm{Cu}$ and Sn precipitate at high temperatures and what role $\mathrm{MnS}$ precipitates play in the successive precipitation behavior of $\mathrm{Cu}$ and $\mathrm{Sn}$ at lower temperatures.

\section{Methods of Experiment and Analysis}

A confocal scanning laser microscope with an infrared image furnace was used to carry out the experiment of in-situ observation of precipitation behavior at high temperatures. The principle and the method of operation of the laser microscope have been described in detail elsewhere. ${ }^{718-25)} \mathrm{Fe}-10$ mass $\% \mathrm{Cu}$ alloys ${ }^{7,18)}$ and $\mathrm{Fe}-$ 
Table 1. Chemical composition of samples (mass $\%$ ).

\begin{tabular}{ccccccccccc}
\hline Sample & {$[\mathrm{C}]$} & {$[\mathrm{Si}]$} & {$[\mathrm{Mn}]$} & {$[\mathrm{P}]$} & {$[\mathrm{S}]$} & {$[\mathrm{Cu}]$} & {$[\mathrm{Sn}]$} & T. [Al] & {$[\mathrm{O}]$} & {$[\mathrm{N}]$} \\
\hline A & 0.0011 & 0.003 & $<0.002$ & 0.010 & $<0.0003$ & 10.03 & 0.48 & 0.002 & 0.0192 & 0.0006 \\
B & 0.0010 & 0.003 & 0.62 & 0.010 & 0.041 & 10.06 & 0.42 & 0.002 & 0.0263 & 0.0006 \\
\hline
\end{tabular}

$0.05 \mathrm{mass} \% \mathrm{C}-\mathrm{Sn}$ steels ${ }^{19)}$ have been already investigated. Based on the previous studies, $\mathrm{Fe}-10 \mathrm{mass} \% \mathrm{Cu}-0.5 \mathrm{mass} \%$ $\mathrm{Sn}$ alloys were chosen in this study. The effect of $\mathrm{Sn}$ on the heterogeneous nucleation of $\mathrm{Cu}$ and $\mathrm{MnS}$ was considered to be so interesting that a large amount of Sn was intentionally added in this study.

Metallic iron, manganese, tin, copper and FeS agent were prepared and melted in the water-cooled copper mould by using an arc furnace with a tungsten electrode under argon atmosphere. Two mother alloys of the button shape of about $60 \mathrm{~mm}$ in diameter, $8 \mathrm{~mm}$ in height and about $120 \mathrm{~g}$ were made. Then the specimen of $4.2 \mathrm{~mm}$ in diameter, $2 \mathrm{~mm}$ in height and about $0.2 \mathrm{~g}$ for the observation experiment was machined from the mother alloy and mirror-polished.

The chemical composition of the samples is given in Table 1. The manganese $(\mathrm{Mn})$ and sulfur $(\mathrm{S})$ contents are very important and varied from zero to $0.6 \%$ and zero to $0.04 \%$ respectively, given approximately the same $\mathrm{Mn} / \mathrm{S}$ ratio according to the previous works. ${ }^{7,18,19)}$ In the previous works $\mathrm{Fe}-10 \% \mathrm{Cu}$ alloys were selected so as to investigate the precipitation of liquid $\mathrm{Cu}$ in $\gamma \mathrm{Fe}$ on the basis of the equilibrium phase diagrams of the $\mathrm{Fe}-\mathrm{Cu}$ binary system. ${ }^{26)}$ In this study the phase diagram of $\mathrm{Fe}-0.5 \mathrm{mass} \% \mathrm{Sn}-\mathrm{Cu}$ quasi-binary system should be determined. Therefore $\mathrm{Fe}-0.5 \mathrm{mass} \% \mathrm{Sn}-0.5 \mathrm{mass} \% \mathrm{Cu}$ alloys and $\mathrm{Fe}-0.5 \mathrm{mass} \% \mathrm{Sn}-$ 10 mass $\% \mathrm{Cu}$ alloys were also made to analyze temperatures of phase transformation and melting points by a differential scanning calorimetry (DSC) method.

In-situ observation of each specimen was carried out under the two cooling conditions as shown in Fig. 1. ${ }^{7,18)}$ The specimen was heated at the rate of $1.7 \mathrm{~K} / \mathrm{s}$ to $1613 \mathrm{~K}$ and kept constant for $1.2 \mathrm{ks}$. Then it was cooled at the rate of $0.33 \mathrm{~K} / \mathrm{s}$ to $1423 \mathrm{~K}$. Two heat patterns were taken below $1423 \mathrm{~K}$. One heat pattern is a continuous cooling pattern at the same rate of $0.33 \mathrm{~K} / \mathrm{s}$. The other is a pattern of holding treatment at $1423 \mathrm{~K}$ for $3.6 \mathrm{Ks}$ followed by cooling at the rate of $0.33 \mathrm{~K} / \mathrm{s}$. This experiment of holding treatment was planned to clarify the precipitation of $\mathrm{Cu}(\mathrm{Sn})$ alloy of liquid phase in $\gamma \mathrm{Fe}$. The images during in-situ observation were continuously recorded on the videotapes and later the images were analyzed in detail.

After the in-situ observation experiment all the specimens were analyzed by SEM and TEM to identify the precipitates. The extracted replica film or a thin film was made for TEM analysis. When the replica film was made to extract precipitates, a special care was taken to prevent the dissolution of $\mathrm{Cu}$ and sulfides into solvent by using the non-aqueous solvent. This no-aqueous electrolyte-potentiostatic etching method is called as SPEED method. ${ }^{27)}$ For making thin films, an ion milling method was used. A field emission type (FE-) TEM operating at $200 \mathrm{kV}$ and a highresolution TEM operating at $300 \mathrm{kV}$ were used. SEM and both TEM are equipped with an energy-dispersed spectroscopy (EDS). The morphology and the composition of the precipitates were investigated and analyzed in detail.

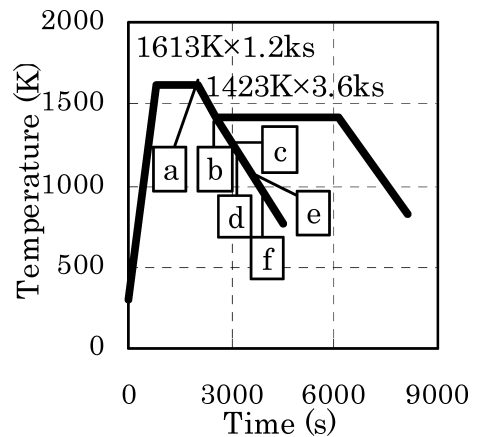

Fig. 1. Two heat patterns for in-situ observation experiment. The indications of a to $f$ are the point where the images will be analyzed.

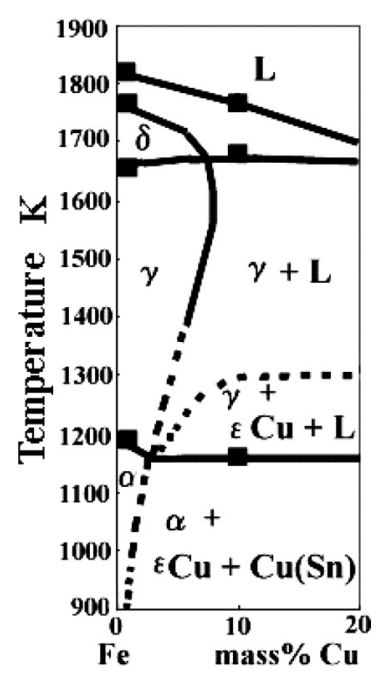

Fig. 2. $\mathrm{Fe}-0.5 \mathrm{mass} \% \mathrm{Sn}-\mathrm{Cu}$ quasi-binary system phase diagram estimated by DSC analysis.

Furthermore the crystal structure of the typical precipitate such as $\mathrm{Cu}, \mathrm{Cu}$ sulfides and $\mathrm{Mn}$ sulfides was determined by the EDS analysis and the electron diffraction technique. The obtained electron diffraction pattern was analyzed and assigned to the JCPDS data system for the d-spacing to identify the precipitates.

\section{Results}

\subsection{Estimation of the Fe-0.5mass $\% \mathrm{Sn}-\mathrm{Cu}$ Quasi-bi- nary System Phase Diagram}

The phase diagram of $\mathrm{Fe}-\mathrm{Cu}-\mathrm{Sn}$ ternary system has not been well established yet especially below $1300 \mathrm{~K}$ in the previous works. ${ }^{1,2,5,28)}$ In order to estimate the phase diagram of $\mathrm{Fe}-0.5 \mathrm{mass} \% \mathrm{Sn}-\mathrm{Cu}$ quasi-binary system DSC analysis was done. Figure 2 shows the estimated $\mathrm{Fe}-$ $0.5 \mathrm{mass} \% \mathrm{Sn}-\mathrm{Cu}$ quasi-binary system phase diagram. The temperatures of the phase transformation and the melting points obtained by DSC were plotted in the figure. Calculated phase diagram was indicated in the same figure. The thermodynamic parameters of Imada et al. ${ }^{29)}$ were used 


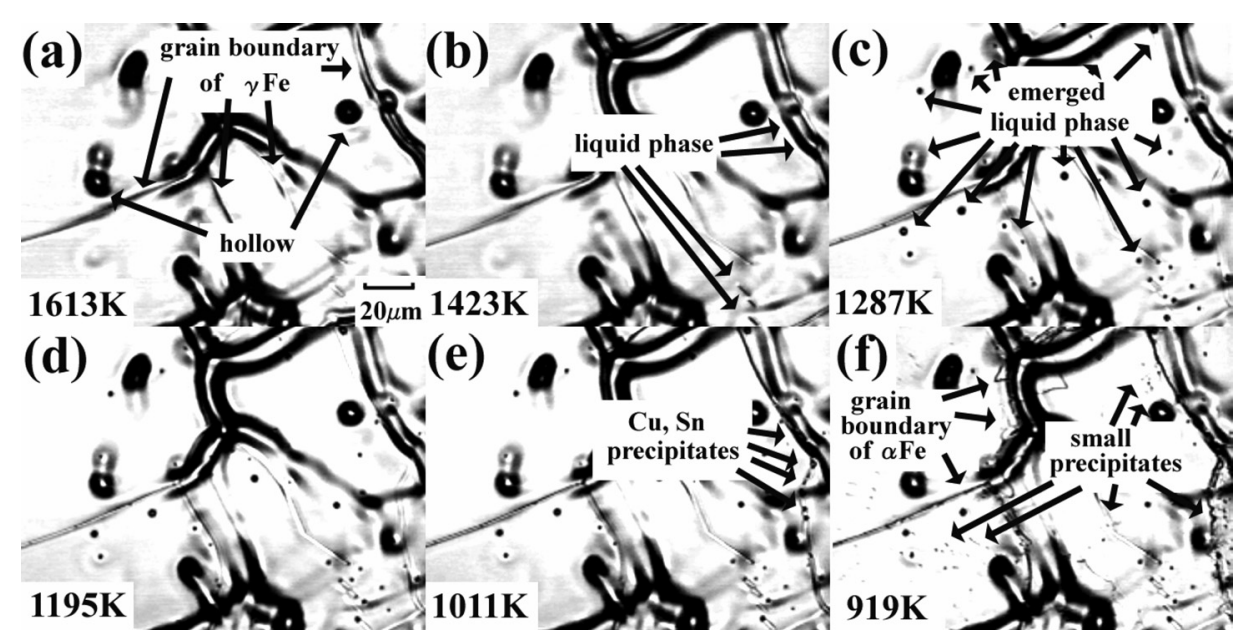

Fig. 3. The sequential images of $\mathrm{Cu}(\mathrm{Sn})$ precipitation observed by the confocal laser microscope in sample $\mathrm{A}$ on the condition of continuous cooling.

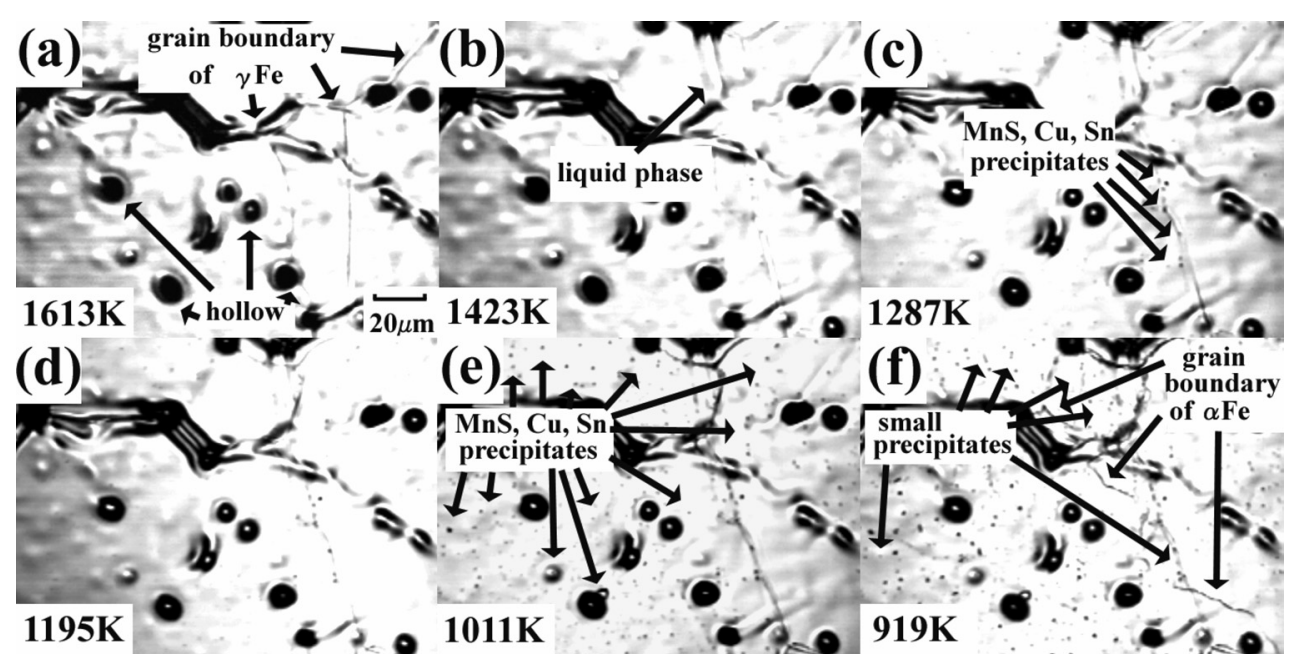

Fig. 4. The sequential images of $\mathrm{MnS}$ and $\mathrm{Cu}(\mathrm{Sn})$ precipitation observed by the confocal laser microscope in sample $\mathrm{B}$ on the condition of continuous cooling.

in the calculation. Dotted lines obtained by calculation were most probably existed but the points were not confirmed in the DSC analysis.

Compared with the equilibrium phase diagram of $\mathrm{Fe}-\mathrm{Cu}$ binary system, ${ }^{26)}$ it is clear that the domain of $\gamma \mathrm{Fe}$ phase becomes smaller and the domain of the liquid phase becomes larger with the addition of $\mathrm{Sn}$. On the basis of these results, it will be expected that hot shortness becomes worse when $\mathrm{Sn}$ coexists with $\mathrm{Cu}$ in steels.

\subsection{In-situ Observation}

The behavior of the precipitation and the phase transformation for the samples A and B on the same condition of continuous cooling were shown in Figs. 3 and $\mathbf{4}$, respectively. The identification of the precipitates has been separately done but it will be described in the later section.

Figure 3 shows the sequential images observed by a confocal laser microscope for sample A without $\mathrm{MnS}$ in the case of the continuous cooling. The alphabetical notation in each image in Fig. 3 corresponds to the point indicated in Fig. 1. As shown in Fig. 3(a), the matrix was $\gamma$ Fe phase at $1613 \mathrm{~K}$. The liquid phase should coexist at this temperature according to the estimated phase diagram. Actually the grain boundaries looked slightly fluctuating during observation indicating the liquid phase at the grain boundary. No precipitates but hollows were observed. These hollows appeared during heating up to $1613 \mathrm{~K}$ and stayed during cooling. As shown in Fig. 3(b), the liquid phase at the grain boundary was more clearly visible and migrating at the grain boundaries. Between Figs. 3(b) and 3(c), the liquid phase spread out at $1420 \mathrm{~K}$ and wetted the surface. The emerged liquid phase gathered and became small particles during cooling as indicated in Figs. 3(c) and 3(d). Below $1060 \mathrm{~K}$ where the liquid phase became solid the precipitates appeared also at the grain boundary as shown in Fig. 3(e). At $974 \mathrm{~K} \gamma / \alpha$ phase transformation occurred and the image at $919 \mathrm{~K}$ is shown in Fig. 3(f). After the phase transformation the numerous small precipitates appeared in the $\alpha \mathrm{Fe}$ grains.

Similarly, Fig. 4 shows the sequential images in sample $\mathrm{B}$ with $\mathrm{MnS}$ in case of continuous cooling. The matrix is $\gamma \mathrm{Fe}$ phase and coexists with the liquid phase fluctuating at the grain boundaries at $1613 \mathrm{~K}$ as shown in Fig. 4(a). No precipitates but hollows were observed. In the case of sample B with $\mathrm{MnS}$, the emergence of the liquid phase was not observed on the surface by contrast to sample A as shown 


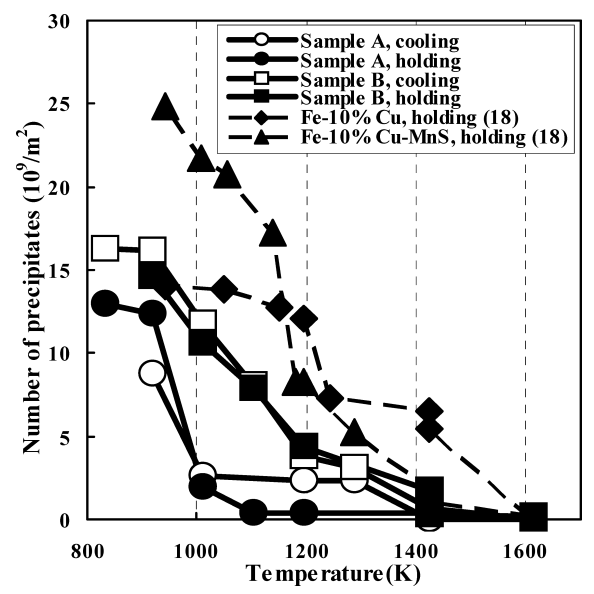

Fig. 5. Change in the number of precipitates with temperature counted on the images. The data from the previous works $^{18)}$ were depicted and compared with the present work.

in Fig. 3(b). Only the liquid phase at the grain boundary was clearly visible as shown in Fig. 4(b). MnS precipitates possibly reduce the enrichment of $\mathrm{Cu}$ at the grain boundary in case of $\mathrm{Fe}-0.5 \mathrm{mass} \% \mathrm{Sn}-\mathrm{Cu}-\mathrm{Mn}-\mathrm{S}$ alloy system.

As shown in Fig. 4(c) $\mathrm{Cu}-\mathrm{Sn}$ precipitates with $\mathrm{MnS}$ were observed along the grain boundary. No other remarkable change was observed until the specimen was cooled below $1110 \mathrm{~K}$ as shown in Fig. 4(d). Then, many tiny precipitates appeared in the grains and grew during cooling down to about $1070 \mathrm{~K}$ as shown in Fig. 4(e). At $973 \mathrm{~K} \gamma / \alpha$ phase transformation occurred and after the phase transformation many small precipitates appeared in the $\alpha \mathrm{Fe}$ grains as shown in Fig. 4(f).

The comparison was made between two conditions of continuous cooling and holding treatment for sample A. The liquid phase was clearly and brightly observed until the specimen was cooled down below $1130 \mathrm{~K}$. On the contrary much more precipitates appeared for sample B in case of holding at $1423 \mathrm{~K}$, This temperature of precipitation was slightly higher than that in continuous cooling condition. Other behaviors were almost the same as mentioned above for both samples A and B.

Based on the above observation by a confocal laser microscope, the number of precipitates was counted. The liquid phase at the grain boundaries was taken into account and counted on the sequential images only after it solidified and the shape of precipitates was confirmed as separate particles. Figure 5 shows the change in the number of precipitates with temperature. The previous data ${ }^{18)}$ are also included in this figure.

There are a couple of characteristics seen in this figure. Firstly, in case of the $\mathrm{Fe}-\mathrm{Cu}-\mathrm{Sn}$ ternary system the difference of the change in number between samples A and B is very large. The number of precipitates in sample B increased at higher temperatures than that in sample A. This increase is due to the precipitation of $\mathrm{MnS}$ at high temperatures.

Secondly the difference for the same sample is very small between two heat patterns. However it should be noted that in case of sample B with $\mathrm{MnS}$ the precipitates appeared during the holding treatment at $1423 \mathrm{~K}$ which is higher than that for the continuous cooling pattern.
Finally comparing the present data with the previous ones for $\mathrm{Fe}-\mathrm{Cu}$ binary system, the increase in the number of precipitates for both samples seems to be delayed at higher temperatures. Sn would certainly be responsible for the difference. In case of $\mathrm{Fe}-\mathrm{Cu}-\mathrm{Sn}$ ternary system the domain of the liquid phase was widened as already shown in Fig. 2 and the liquid precipitates at grain boundaries were often observed in the microscope at lower temperatures. It is neither accurate nor suitable to count the number of the liquid precipitates of a linear shape on the image analysis. This shape of liquid precipitates is responsible for the apparent difference between the binary and the ternary systems. Nevertheless once the liquid phase solidifies below $1060 \mathrm{~K}$, the increase in the number of precipitates is meaningful. After $\gamma / \alpha$ phase transformation, many small precipitates were observed and the number increased sharply. This behavior is similar to that in $\mathrm{Fe}-0.05$ mass $\% \mathrm{C}-\mathrm{Sn}$ system. ${ }^{19)}$

\section{Discussion}

The morphology, the composition and the crystal structure of the precipitates are discussed in detail as compared with the precipitation behavior in this section. Figure 6 shows the typical precipitates by SEM analysis. The top half of figure is one for sample A and the bottom half for sample B. The left half of figure is one in the case of continuous cooling and the right half in the case of holding treatment. The morphology is classified into three types, "I", "II" and "III" for any cases as shown in Fig. 6. Type "I" is the precipitate at the $\gamma \mathrm{Fe}$ grain boundary as shown in Figs. 6(a) and 6(b). The morphology is lens-like and each size is larger than about $1 \mu \mathrm{m}$. The precipitates aligned at the grain boundaries indicate a liquid film at high temperatures. The precipitates are also equivalent to the liquid phase emerging in the $\gamma \mathrm{Fe}$ grains at high temperature as previously shown in Figs. 3(c) and 3(d). The composition is analyzed and later shown to make confirmation.

Type "II" is the precipitate of the irregular shape found in the $\gamma \mathrm{Fe}$ grains and the size is between $300 \mathrm{~nm}$ and $10 \mu \mathrm{m}$. A big finger-like precipitate seen in Fig. 6(c) is very interesting because a kind of nucleus seems to exist at the junction of three fingers. Type "III" is the smallest precipitate in the $\alpha \mathrm{Fe}$ grains. They nucleated after $\gamma / \alpha$ phase transformation and the size is less than $100 \mathrm{~nm}$.

Figure 7 shows the detail of type "I" precipitate of about $1 \mu \mathrm{m}$ size in sample B analyzed by TEM. This figure corresponds to the precipitate in Fig. 6(d). The composition of the precipitate at the grain boundary indicated as 1 in Fig. 7(a) was analyzed by EDS as shown in Fig. 7(b). The crystal structure was identified by the electron diffraction pattern as shown in Fig. 7(c). As a result the composition of the precipitate is determined as $\mathrm{Cu}$ containing a small amount of $\mathrm{Sn}$. The crystal structure is the same fcc structure as $\varepsilon \mathrm{Cu}$. Apparently this $\mathrm{Cu}$ containing $\mathrm{Sn}$ is solid solution and defined as $\alpha \mathrm{Cu}$ in the $\mathrm{Cu}-\mathrm{Sn}$ phase diagram. ${ }^{30}$ )

The above confirmation by TEM has been repeated on some other precipitates. The type "I" precipitates in sample B is different from those in sample A. In the case of sample A without $\mathrm{MnS}$, the type "I" precipitates are mainly $\mathrm{Cu}(\mathrm{Sn})$ solid solution and the size is between 0.5 and 10 $\mu \mathrm{m}$. Some precipitates in the $\gamma \mathrm{Fe}$ grains are found to con- 


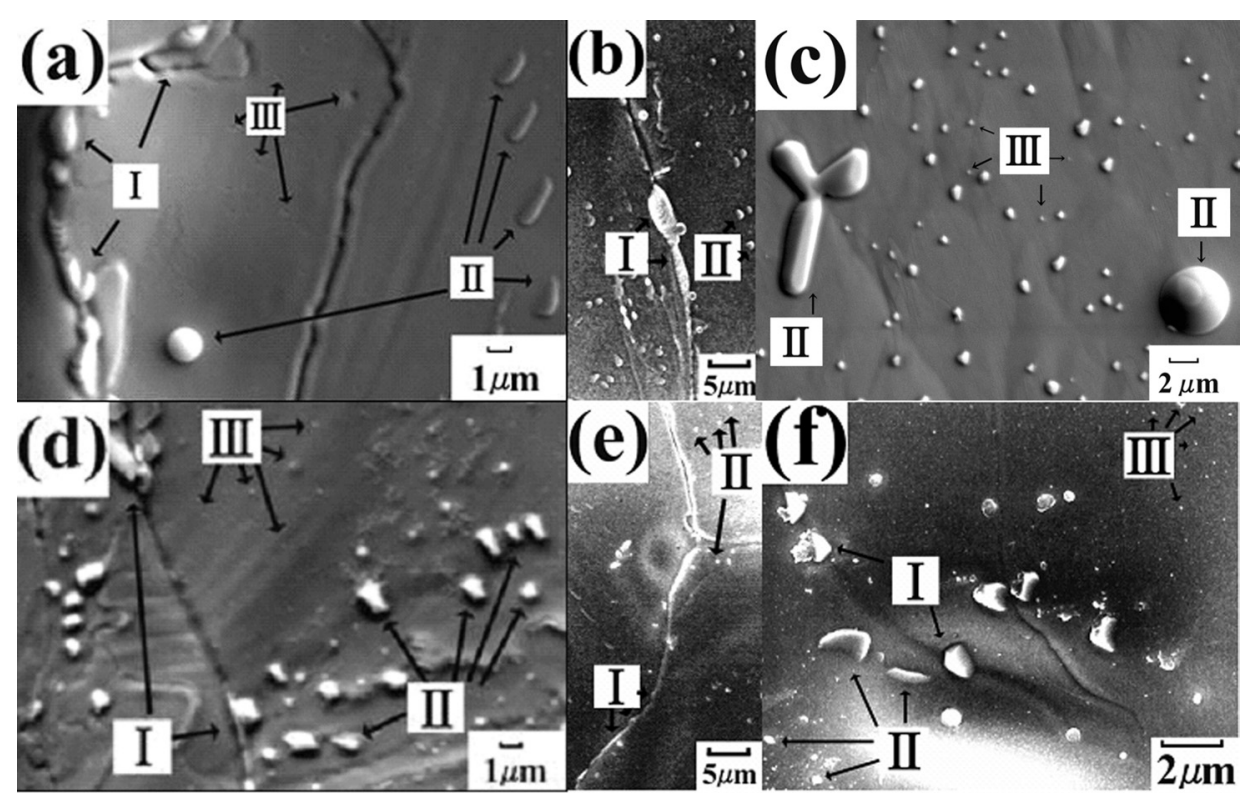

Fig. 6. SEM images of three types of the precipitates, I, II and III. (a): sample A, continuous cooling, (b) and (c): sample A, holding treatment, (d): sample B, continuous cooling, (e) and (f): sample B, holding treatment.

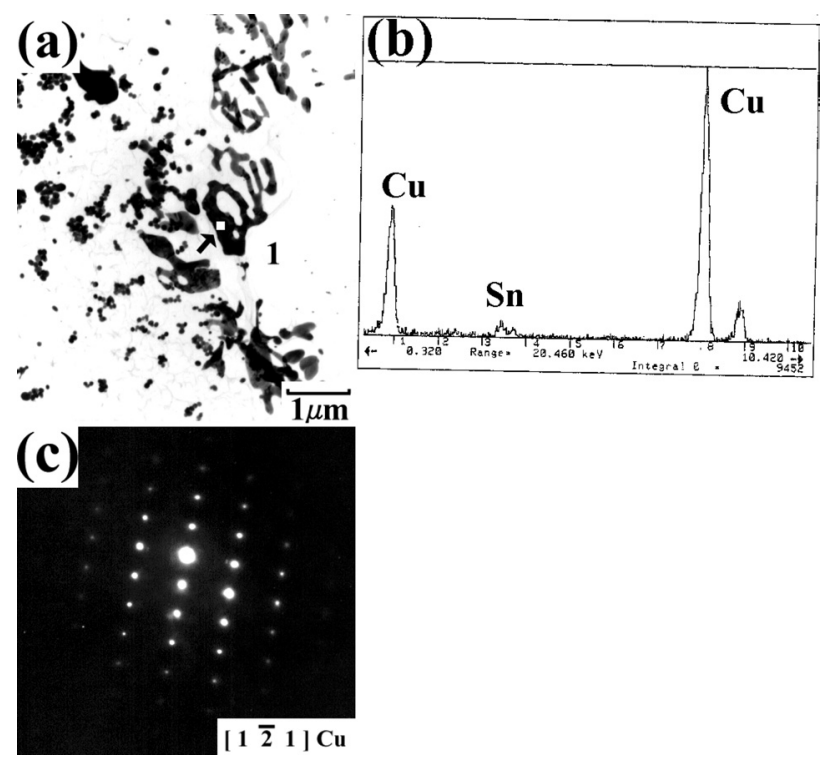

Fig. 7. The detail of Type I precipitates analyzed by TEM indicating $\mathrm{Cu}-\mathrm{Sn}$ alloy in sample B. The figure corresponds to Fig. 6(d).

tain aluminum and silicon oxide inclusion.

On the contrary in the case of sample B with $\mathrm{MnS}$, the precipitate of about $1 \mu \mathrm{m}$ size found at the grain boundary is identified as $(\mathrm{Mn}, \mathrm{Cu})$ sulfide precipitate by EDS analysis. It is interesting to suggest that this $(\mathrm{Mn}, \mathrm{Cu}) \mathrm{S}$ precipitate is the complex of $\mathrm{MnS}$ with $\mathrm{Cu}(\mathrm{Sn})$ precipitates. In the case of sample B containing both $\mathrm{Mn}$ and $\mathrm{S}, \mathrm{MnS}$ precipitates firstly nucleate at higher temperatures and then $\mathrm{Cu}$ (Sn) precipitates nucleate at $\mathrm{MnS}$ precipitate by the heterogeneous nucleation principle. Thus the precipitate ends up with the complex precipitates of $(\mathrm{Mn}, \mathrm{Cu}) \mathrm{S}$. It is clear that $\mathrm{Cu}$ precipitate is liquid at the grain boundaries at high temperatures and solidifies later at lower temperatures to form $\mathrm{Cu}(\mathrm{Sn})$ or $(\mathrm{Mn}, \mathrm{Cu}) \mathrm{S}$ precipitates as shown in Fig. 7(a).

Next, Figs. 8 and 9 show the detail of type "II" precipitate in sample B in the case of continuous cooling. The pre-

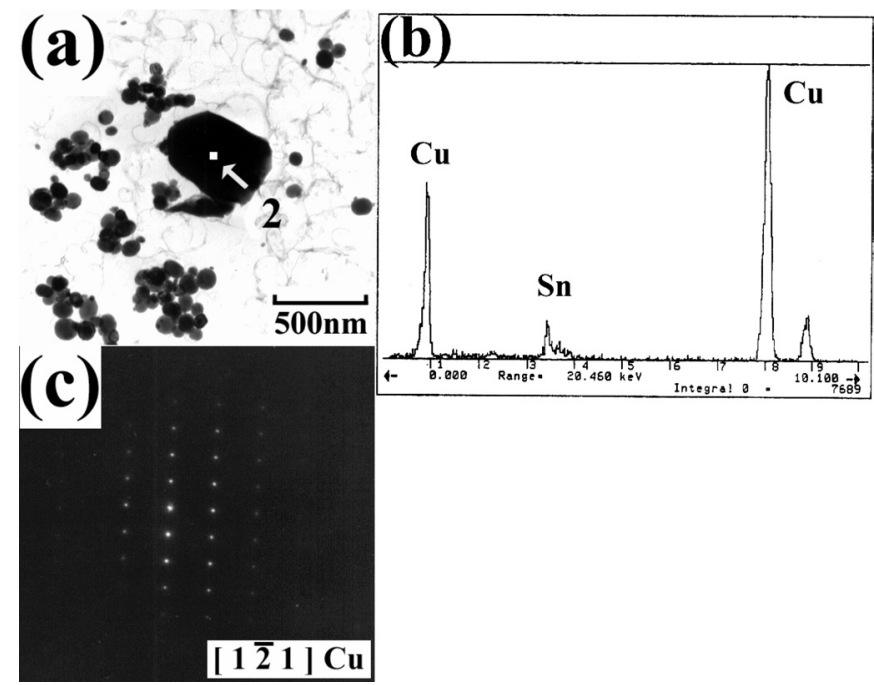

Fig. 8. TEM micrographs of $\mathrm{Cu}(\mathrm{Sn})$ classified into type "II" in sample B in the case of continuous cooling.

cipitate of $300 \mathrm{~nm}$ indicated as 2 in Fig. 8 was analyzed by TEM and it is identified as $\mathrm{Cu}(\mathrm{Sn})$ solid solution with fcc crystal structure. Another complex precipitate of about $300 \mathrm{~nm}$ as shown in Fig. 9 was also analyzed by TEM. The composition at the points indicated as 3,4 and 5 is different, respectively. This complex precipitate is composed of $\varepsilon \mathrm{Cu},(\mathrm{Mn}, \mathrm{Cu}) \mathrm{S}$ and $\mathrm{Cu}_{7.2} \mathrm{~S}_{4}$. The small particle of about $100 \mathrm{~nm}$ size indicated as 3 is identified as $\varepsilon \mathrm{Cu}$. It is found that two larger precipitates indicated as 4 and 5 do not contain Sn, respectively. The part indicated as 4 is $(\mathrm{Mn}, \mathrm{Cu}) \mathrm{S}$ and the part indicated as 5 is $\mathrm{Cu}$ sulfide by EDS analysis. The latter part indicated as 5 was analyzed by the electron diffraction as shown in Fig. 9(e) and is identified as $\mathrm{Cu}_{7.2} \mathrm{~S}_{4}$ with the fcc crystal structure of 5.57 angstrom lattice constant. Thus MnS precipitate nucleate at first and it is followed by $\mathrm{Cu}$ precipitate to form $(\mathrm{Mn}, \mathrm{Cu}) \mathrm{S}$ and $\mathrm{Cu}_{7.2} \mathrm{~S}_{4}$. Finally $\varepsilon \mathrm{Cu}$ precipitate nucleates at the above complex precipitate to end up with type "II" precipitates. 


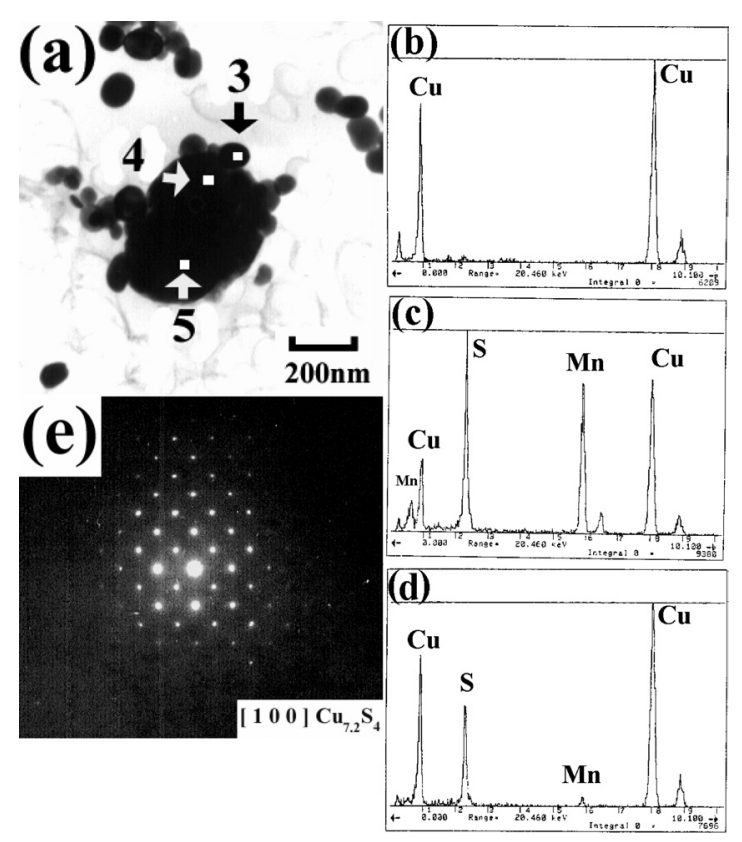

Fig. 9. TEM micrographs of $(\mathrm{Mn}, \mathrm{Cu}) \mathrm{S}, \mathrm{Cu}$ and $\mathrm{Cu}_{7.2} \mathrm{~S}_{4}$ precipitates in sample $\mathrm{B}$ in the case of continuous cooling.

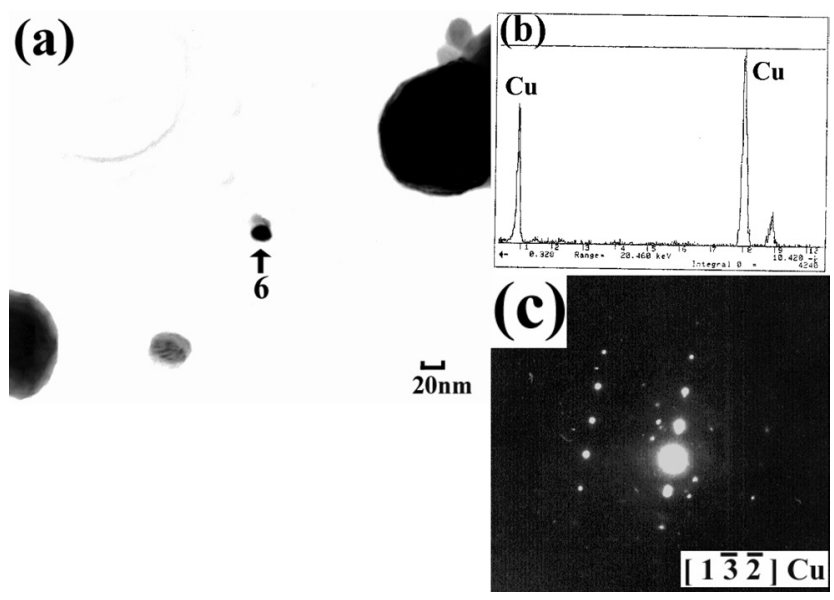

Fig. 10. TEM micrographs of $\mathrm{Cu}$ precipitate in sample $\mathrm{B}$ in the case of continuous cooling.

This finding is similar to the previous work $^{18)}$ for $\mathrm{Fe}-10$ mass $\% \mathrm{Cu}-\mathrm{Mn}-\mathrm{S}$ system without $\mathrm{Sn}$ where $\mathrm{MnS}$ precipitate of $200 \mathrm{~nm}$ size was surrounded by $\mathrm{Cu}_{7.2} \mathrm{~S}_{4}$ precipitate in the case of continuous cooling. Again the heterogeneous nucleation mechanism is important. Because this heterogeneous nucleation with $\mathrm{MnS}$ occurs at high temperatures in sample B, the number of precipitates starts to increase at high temperature as shown in Figs. 4 and 5.

Figure 10 shows the detail of type "III" precipitate, extremely fine $\mathrm{Cu}$ particle of $15 \mathrm{~nm}$ sizes. The precipitate indicated as 6 is analyzed to be $\varepsilon \mathrm{Cu}$ particle with fcc crystal structure of 3.615 angstrom lattice constant. It is worth to mention that the precipitates smaller than about $50 \mathrm{~nm}$ classified as type "III" are $\varepsilon \mathrm{Cu}$ and do not contain $\mathrm{Sn}$.

On the contrary, relatively larger particles than $100 \mathrm{~nm}$ classified as type "II" precipitates contain some Sn. Sn exists only in the liquid $\mathrm{Cu}$ film at the grain boundaries and also in the relatively larger $\mathrm{Cu}$ particles in the $\gamma \mathrm{Fe}$ grains. $\mathrm{Sn}$ is so easily dissolved into the liquid $\mathrm{Cu}$ phase that the domain of the liquid phase is widened. When MnS coexists with $\mathrm{Sn}$ both at the grain boundaries and in the $\gamma \mathrm{Fe}$ grains, the heterogeneous nucleation of liquid $\mathrm{Cu}, \mathrm{Cu}(\mathrm{Sn})$ and $\mathrm{Cu}$ sulfide will nucleate at $\mathrm{MnS}$ precipitates.

\section{Conclusions}

In order to evaluate the effect of Sn on the heterogeneous nucleation of $\mathrm{MnS}$ and $\mathrm{Cu}$ precipitates, the in-situ observation experiment was carried out for the $\mathrm{Fe}-10 \mathrm{mass} \% \mathrm{Cu}-$ $0.5 \mathrm{mass} \% \mathrm{Sn}$ ternary alloys by using a confocal scanning laser microscope. The effect of the addition of $\mathrm{Mn}$ and $\mathrm{S}$ on the behavior of $\mathrm{Cu}$ precipitates was investigated in detail under the different heat pattern. The main results obtained are summarized as follows:

The precipitates are classified into three types. Type "I" is the liquid $\mathrm{Cu}(\mathrm{Sn})$ nucleating at the $\gamma \mathrm{Fe}$ grain boundaries with or without MnS. Type "II" is the complex of $\mathrm{Cu}(\mathrm{Sn})$, $\mathrm{Cu}$ and $\mathrm{Cu}_{7.2} \mathrm{~S}_{4}$ precipitates. These are heterogeneously nucleated at $\mathrm{MnS}$ or oxide precipitates in the grains. The size of type "I" is larger than about $1 \mu \mathrm{m}$. The sizes of type "II" are $0.3-10 \mu \mathrm{m}$ and type "III" is less than $100 \mathrm{~nm}$. The many extremely fine $\varepsilon \mathrm{Cu}$ precipitates of $15 \mathrm{~nm}$ with fcc crystal structure were found in the $\alpha \mathrm{Fe}$ grains.

The domain of liquid phase is widened by the addition of $\mathrm{Sn}$ to the $\mathrm{Fe}-10$ mass $\% \mathrm{Cu}$ alloys. This is the direct evidence why hot shortness gets worse with the coexistence of $\mathrm{Sn}$ with $\mathrm{Cu}$ in steels.

It is most interesting to find that the addition of $\mathrm{Mn}$ and $\mathrm{S}$ enhances the heterogeneous nucleation to form many small particles of $\mathrm{Cu}(\mathrm{Sn})$, complex precipitates combined with $\mathrm{MnS}$ of $100-500 \mathrm{~nm}$ size and many extra fine particles of $\mathrm{Cu}$ less than $50 \mathrm{~nm}$ in the $\alpha \mathrm{Fe}$ grains. The temperature of precipitation with $\mathrm{MnS}$ in the $\gamma \mathrm{Fe}$ grain is elevated by the addition of $\mathrm{Mn}$ and $\mathrm{S}$. Compared with the behavior in $\mathrm{Fe}-10 \mathrm{mass} \% \mathrm{Cu}$ binary system, the effect of $\mathrm{MnS}$ is weakened by $\mathrm{Sn}$ addition. However the coexistence of $\mathrm{Mn}$ and $\mathrm{S}$ in $\mathrm{Fe}-\mathrm{Cu}-\mathrm{Sn}$ ternary system, the positive effect of $\mathrm{MnS}$ is still apparent. That is to say, it will be expected that $\mathrm{Cu}$ precipitation at the grain boundaries is reduced and hot shortness is avoided. Therefore $\mathrm{Cu}$ and $\mathrm{Sn}$ will be considered not as tramp elements but active alloying elements.

\section{Acknowledgement}

The financial support by SIFAEPT (Steel Industry Foundation for the Advancement of Environmental Protection Technology), Sumitomo Metals Industries and Nippon Steel Corporation is sincerely acknowledged. The authors wish to thank Professor M. Hasebe in Kyusyu Institute Technology and Mr. A. Kiyose in Nippon Steel Corporation for their helps in calculation of equilibrium phase diagram by using the THERMO-CALC software program. The authors also wish to thank Mr. K. Nakamura in Nippon Steel Technoresearch for his help in TEM analysis.

\section{REFERENCES}

1) K. Born: Stahl Eisen, 73 (1953), 1268.

2) D. A. Melford: J. Iron Steel. Inst., 200 (1962), 290.

3) A. Nicholson and J. D. Murray: J. Iron Steel. Inst., 203 (1965), 1007.

4) T. Kajitani, M. Wakoh, N. Tokumitsu, S. Ogibayashi and S. Mizoguchi: Tetsu-to-Hagané, 81 (1995), 185.

5) N. Imai, N. Komatsubara and K. Kunishige: ISIJ Int., 37 (1997), 217.

6) S. Seo, K. Asakura and K. Shibata: ISIJ Int., 37 (1997), 240. 
7) H. Hasegawa, K. Nakajima and S. Mizoguchi: ISIJ Int., 43 (2003), 1021.

8) R. L. Rickett and W. C. Leslie: Trans. Am. Soc. Met., 51 (1959), 310.

9) H. Abe, T. Suzuki, F. Togawa and N. Miyasaka: Tetsu-to-Hagané, 60 (1974), 1496.

10) H. Era, M. Shimizu and T. Hiruta: Tetsu-to-Hagané, 70 (1984), 1946.

11) T. Yamada, M. Oda and O. Akisue: Tetsu-to-Hagané, 79 (1993), 973.

12) J. Syarif, T. Hoshino, T. Tsuchiyama and S. Takaki: Tetsu-toHagané, 86 (2000), 558.

13) K. Nakashima, Y. Futamura, T. Tsuchiyama and S. Takaki: Tetsu-toHagané, 89 (2003), 524.

14) K. Kishida and O. Akisue: Tetsu-to-Hagané, 76 (1990), 759.

15) M. Morita, K. Sato and Y. Hosoya: Tetsu-to-Hagané, 80 (1994), 48.

16) W. C. Leslie, J. T. Michalak and F. W. Aul: Iron and Its Dilute Solid Solutions, ed. by C. W. Spencer and F. E. Werner, Interscience, New York, (1963), 119.

17) A. Ohmori, A. Matsuzaki and K. Amano: ISIJ Int., 37 (1997), 302.

18) K. Yamamoto, H. Shibata, K. Nakajima and S. Mizoguchi: Tetsu-toHagané, 90 (2004), 781.

19) K. Yamamoto, H. Shibata, K. Nakajima and S. Mizoguchi: Tetsu-to-
Hagané, 90 (2004), 788.

20) H. Yin, H. Shibata, T. Emi and M. Suzuki: ISIJ Int., 37 (1997), 936.

21) H. Shibata, H. Yin, S. Yoshinaga, T. Emi and M. Suzuki: ISIJ Int., 38 (1998), 149.

22) S. Kimura, Y. Nabeshima, K. Nakajima and S. Mizoguchi: Metall. Mater. Trans. B, 31B (2000), 1013.

23) H. Hasegawa, K. Nakajima and S. Mizoguchi: Tetsu-to-Hagané, 87 (2001), 433.

24) H. Hasegawa, K. Nakajima and S. Mizoguchi: Tetsu-to-Hagané, 87 (2001), 700.

25) S. Kimura, K. Nakajima, S. Mizoguchi and H. Hasegawa: Metall. Mater. Trans. A, 33A (2002), 427.

26) ASM Handbook Vol. 3 Alloy Phase Diagrams, ed. by H. Baker, ASM International, Ohio, (1992), 2.

27) F. Kurosawa, I. Taguchi and R. Matsumoto: J. Jpn. Inst. Met., 11 (1979), 1068.

28) H. Ohtani, H. Suda and K. Ishida: ISIJ Int., 37 (1997), 207.

29) F. Imada, T. Jyodai, M. Hasebe, N. Murakami and T. Kobayashi: CAMP-ISIJ, 7 (1994), 886.

30) ASM Handbook Vol. 3 Alloy Phase Diagrams, ed. by H. Baker, ASM International, Ohio, (1992), 2. 